\title{
A New Family of Fourth-Order Optimal Iterative Schemes and Remark on Kung and Traub's Conjecture
}

\author{
Chein-Shan Liu $\mathbb{D}^{1}$ and Tsung-Lin Lee $\mathbb{D}^{2}$ \\ ${ }^{1}$ Center of Excellence for Ocean Engineering, Center of Excellence for the Oceans, National Taiwan Ocean University, \\ Keelung 202-24, Taiwan \\ ${ }^{2}$ Department of Applied Mathematics, National Sun Yat-sen University, Kaohsiung 80424, Taiwan \\ Correspondence should be addressed to Tsung-Lin Lee; leetsung@math.nsysu.edu.tw
}

Received 12 January 2021; Accepted 1 February 2021; Published 17 February 2021

Academic Editor: Xiaolong Qin

Copyright (C) 2021 Chein-Shan Liu and Tsung-Lin Lee. This is an open access article distributed under the Creative Commons Attribution License, which permits unrestricted use, distribution, and reproduction in any medium, provided the original work is properly cited.

\begin{abstract}
Kung and Traub conjectured that a multipoint iterative scheme without memory based on $m$ evaluations of functions has an optimal convergence order $p=2^{m-1}$. In the paper, we first prove that the two-step fourth-order optimal iterative schemes of the same class have a common feature including a same term in the error equations, resorting on the conjecture of Kung and Traub. Based on the error equations, we derive a constantly weighting algorithm obtained from the combination of two iterative schemes, which converges faster than the departed ones. Then, a new family of fourth-order optimal iterative schemes is developed by using a new weight function technique, which needs three evaluations of functions and whose convergence order is proved to be $p=2^{3-1}=4$.
\end{abstract}

\section{Introduction}

The most basic problem in engineering and scientific applications is to find the root of a given nonlinear equation

$$
f(x)=0,
$$

where $f \in \mathscr{C}(I, \mathbb{R})$ and $I \subset \mathbb{R}$ is an interval we are interested in, and we suppose that $r \in I$ is a simple solution with $f(r)=$ 0 and $f^{\prime}(r) \neq 0$.

The famous Newton method (NM) for iteratively solving equation (1) is given by

$$
x_{n+1}=x_{n}-\frac{f\left(x_{n}\right)}{f^{\prime}\left(x_{n}\right)}, \quad n=0,1, \ldots,
$$

which is quadratically convergent. Due to its simplicity and rapid convergence, the Newton method is still the first choice to solve equation (1).

An extension of the NM to a third-order iterative scheme was made by Halley [1]:

$$
x_{n+1}=x_{n}-\frac{2 f\left(x_{n}\right) f^{\prime}\left(x_{n}\right)}{2 f^{\prime}\left(x_{n}\right)^{2}-f\left(x_{n}\right) f^{\prime \prime}\left(x_{n}\right)} .
$$

For the engineering design of the vibrating modes of an elastic system, sometimes we may need to know the eigenvalues of a large-size square matrix, which results in a highly nonlinear and high-order polynomial equation. More often, the function $f(x)$ is itself obtained from other nonlinear ordinary differential equations or partial differential equations. In this situation, it is hard to calculate $f^{\prime \prime}(x)$ when we apply the Halley method to solve the nonlinear problem.

Kung and Traub conjectured that a multipoint iteration without memory based on $m$ evaluations of functions has an optimal convergence order $p=2^{m-1}$. It means that the upper bound of the efficiency index (E.I.) $=p^{(1 / m)}$ is $2^{(1-1 / m)}<2$. For $m=2$, the NM is one of the second-order optimal iterative schemes; however, with $m=3$, the Halley method is not the optimal one whose E.I. $=1.44225$ is low.

The pioneering work of Newton has inspired a lot of studies to solve nonlinear equations, whereby different fourth-order iterative methods were developed for more quickly and stably 
solving nonlinear equations [2-9]. Many methods to construct the two-step fourth-order optimal schemes were based on the operations of $\left[f\left(x_{n}\right), f^{\prime}\left(x_{n}\right), f\left(y_{n}\right)\right]$ where $y_{n}$ is obtained from the first Newton step [2, 4-8, 10-14]. Recently, Chicharro et al. [9] proposed a new technique to construct the optimal fourth-order iterative schemes based on the weight function technique.

\section{Preliminaries}

Before deriving the main results in the next section, we begin with some standard terminologies.

Definition 1. Let the iterative sequence $\left\{x_{n}\right\}$ generated from an iterative scheme converge to a simple root $r$. If there exists a positive integer $p$ and a real number $C$ such that

$$
\lim _{n \longrightarrow \infty} \frac{x_{n+1}-r}{\left(x_{n}-r\right)^{p}}=C,
$$

then $p$ is the order of convergence and $C$ is the asymptotic error constant.

Let $e_{n}=x_{n}-r$ be the error in the $n$th iterate. Then, the relation

$$
e_{n+1}=C e_{n}^{p}+\mathcal{O}\left(e_{n}^{p+1}\right),
$$

is called the error equation of an iterative scheme. For example, for the Newton method, the error equation reads as

$$
e_{n+1}=c_{2} e_{n}^{2}+\mathcal{O}\left(e_{n}^{3}\right)
$$

where

$$
c_{n}:=\frac{f^{(n)}(r)}{n ! f^{\prime}(r)}, \quad n=2, \ldots
$$

Definition 2 (see [10]). An iterative scheme is said to have the optimal order $p$, if $p=2^{m-1}$ where $m$ is the number of evaluations of functions (including derivatives).

Definition 3. The efficiency index (E.I.) of an iterative scheme is defined by E.I. $=p^{(1 / m)}$.

Definition 4. The conjecture of Kung and Traub asserted that a multipoint iteration without memory based on $m$ evaluations of functions has an optimal order $p=2^{m-1}$ of convergence [11]. It indicates that the upper bound of the efficiency index is $2^{(1-1 / m)}<2$.

Definition 5. The iterative schemes are of the same class, if they are of the same order $p$ and have the same $m$ evaluations of the same functions.

\section{Main Results}

We begin with the error equation of the NM:

$$
e_{n+1}=c_{2} e_{n}^{2}-A_{3} e_{n}^{3}-A_{4} e_{n}^{4}+\cdots
$$

where

$$
\begin{aligned}
& A_{3}=2 c_{2}^{2}-2 c_{3}, \\
& A_{4}=7 c_{2} c_{3}-4 c_{2}^{3}-3 c_{4} .
\end{aligned}
$$

Refer the papers, for instance, $[6,12,13]$.

Throughout of the paper, we fix the following notation:

$$
y_{n}=x_{n}-\frac{f\left(x_{n}\right)}{f^{\prime}\left(x_{n}\right)},
$$

which is the first step of many two-step iterative schemes.

We summarize some fourth-order optimal iterative schemes which were modified from the NM by Chun [14]:

$$
\left\{\begin{array}{l}
x_{n+1}=x_{n}-\frac{f\left(x_{n}\right)}{f^{\prime}\left(x_{n}\right)}-\left(\frac{f\left(x_{n}\right)}{f\left(x_{n}\right)-f\left(y_{n}\right)}\right)^{2} \frac{f\left(y_{n}\right)}{f^{\prime}\left(x_{n}\right)}, \\
e_{n+1}=\left(2 c_{2}^{3}-c_{2} c_{3}\right) e_{n}^{4}+\cdots,
\end{array}\right.
$$

$\left\{\begin{array}{l}x_{n+1}=x_{n}-\frac{f\left(x_{n}\right)}{f^{\prime}\left(x_{n}\right)}-\frac{f^{2}\left(x_{n}\right)}{f^{2}\left(x_{n}\right)-2 f\left(x_{n}\right) f\left(y_{n}\right)+2 f^{2}\left(y_{n}\right)} \frac{f\left(y_{n}\right)}{f^{\prime}\left(x_{n}\right)}, \\ e_{n+1}=\left(3 c_{2}^{3}-c_{2} c_{3}\right) e_{n}^{4}+\cdots,\end{array}\right.$

by Chun [4]:

$$
\left\{\begin{array}{l}
x_{n+1}=x_{n}-\frac{f\left(x_{n}\right)}{f^{\prime}\left(x_{n}\right)}-\left(1+2 \frac{f\left(y_{n}\right)}{f\left(x_{n}\right)}+\frac{f^{2}\left(y_{n}\right)}{f^{2}\left(x_{n}\right)}\right) \frac{f\left(y_{n}\right)}{f^{\prime}\left(x_{n}\right)} \\
e_{n+1}=\left(4 c_{2}^{3}-c_{2} c_{3}\right) e_{n}^{4}+\cdots,
\end{array}\right.
$$

$$
\left\{\begin{array}{l}
x_{n+1}=x_{n}-\frac{f\left(x_{n}\right)}{f^{\prime}\left(x_{n}\right)}-\left(1+2 \frac{f\left(y_{n}\right)}{f\left(x_{n}\right)}\right) \frac{f\left(y_{n}\right)}{f^{\prime}\left(x_{n}\right)}, \\
e_{n+1}=\left(5 c_{2}^{3}-c_{2} c_{3}\right) e_{n}^{4}+\cdots,
\end{array}\right.
$$

by King [5]:

$$
\left\{\begin{array}{l}
x_{n+1}=x_{n}-\frac{f\left(x_{n}\right)}{f^{\prime}\left(x_{n}\right)}-\frac{f\left(x_{n}\right)+\gamma f\left(y_{n}\right)}{f\left(x_{n}\right)+(\gamma-2) f\left(y_{n}\right)} \frac{f\left(y_{n}\right)}{f^{\prime}\left(x_{n}\right)}, \\
e_{n+1}=\left[(1+2 \gamma) c_{2}^{3}-c_{2} c_{3}\right] e_{n}^{4}+\cdots,
\end{array}\right.
$$


where $\gamma \in \mathbb{R}$, by Chun and Ham [2]:

$$
\left\{\begin{array}{l}
x_{n+1}=x_{n}-\frac{f\left(x_{n}\right)}{f^{\prime}\left(x_{n}\right)}-\frac{4 f^{2}\left(x_{n}\right)+6 f\left(x_{n}\right) f\left(y_{n}\right)+3 f^{2}\left(y_{n}\right)}{4 f^{2}\left(x_{n}\right)-2 f\left(x_{n}\right) f\left(y_{n}\right)-f^{2}\left(y_{n}\right)} \frac{f\left(y_{n}\right)}{f^{\prime}\left(x_{n}\right)}, \\
e_{n+1}=\left(3 c_{2}^{3}-c_{2} c_{3}\right) e_{n}^{4}+\cdots,
\end{array}\right.
$$

by Kuo et al. [8]:

$$
\left\{\begin{array}{l}
x_{n+1}=x_{n}-\frac{f^{2}\left(x_{n}\right)+f^{2}\left(y_{n}\right)}{f^{\prime}\left(x_{n}\right)\left[f\left(x_{n}\right)-f\left(y_{n}\right)\right]} \\
e_{n+1}=\left(3 c_{2}^{3}-c_{2} c_{3}\right) e_{n}^{4}+\cdots
\end{array}\right.
$$

by Ostrowski [15]:

$$
\left\{\begin{array}{l}
x_{n+1}=x_{n}-\frac{f\left(x_{n}\right)\left[f\left(x_{n}\right)-f\left(y_{n}\right)\right]}{f^{\prime}\left(x_{n}\right)\left[f\left(x_{n}\right)-2 f\left(y_{n}\right)\right]} \\
e_{n+1}=\left(c_{2}^{3}-c_{2} c_{3}\right) e_{n}^{4}+\cdots
\end{array}\right.
$$

by Maheshwari et al. [16]:

$$
\left\{\begin{array}{l}
x_{n+1}=x_{n}-\frac{f\left(x_{n}\right)}{f^{\prime}\left(x_{n}\right)}\left[\frac{f^{2}\left(y_{n}\right)}{f^{2}\left(x_{n}\right)}+\frac{f\left(x_{n}\right)}{f\left(x_{n}\right)-f\left(y_{n}\right)}\right], \\
e_{n+1}=\left(4 c_{2}^{3}-c_{2} c_{3}\right) e_{n}^{4}+\cdots,
\end{array}\right.
$$

and by Ghanbari [12]:

$$
\begin{aligned}
& \left\{\begin{array}{l}
x_{n+1}=x_{n}-\frac{f\left(x_{n}\right)}{f^{\prime}\left(x_{n}\right)}-\left(\frac{f\left(x_{n}\right)+2 f\left(y_{n}\right)}{f\left(x_{n}\right)+f\left(y_{n}\right)}\right)^{2} \frac{f\left(y_{n}\right)}{f^{\prime}\left(x_{n}\right)} \\
e_{n+1}=\left(6 c_{2}^{3}-c_{2} c_{3}\right) e_{n}^{4}+\cdots,
\end{array}\right. \\
& \left\{\begin{array}{l}
x_{n+1}=x_{n}-\frac{f\left(x_{n}\right)}{f^{\prime}\left(x_{n}\right)}-\frac{f\left(x_{n}\right)+f\left(y_{n}\right)}{f\left(x_{n}\right)-f\left(y_{n}\right)} \frac{f\left(y_{n}\right)}{f^{\prime}\left(x_{n}\right)} \\
e_{n+1}=\left(3 c_{2}^{3}-c_{2} c_{3}\right) e_{n}^{4}+\cdots .
\end{array}\right.
\end{aligned}
$$

It is interesting that the iterative schemes (12)-(22) are of the same class because they have same convergence order $p=4$ and operated with the same evaluations on $\left[f\left(x_{n}\right), f^{\prime}\left(x_{n}\right), f\left(y_{n}\right)\right]$. The efficiency index (E.I.) of the above eleven iterative schemes is the same $\sqrt[3]{4}=1.5874$, and they are of the optimal fourth-order iterative schemes with three evaluations of $\left[f\left(x_{n}\right), f^{\prime}\left(x_{n}\right), f\left(y_{n}\right)\right]$ in the sense of Kung and Traub, such that $p=2^{m-1}=4$. They belong to the same class with the error equations having a common type:

$$
e_{n+1}=\left(a_{i} c_{2}^{3}-c_{2} c_{3}\right) e_{n}^{4}+\mathcal{O}\left(e_{n}^{5}\right)
$$

where $a_{i}$ are different constants for different optimal fourthorder iterative schemes, which may be zero. Can we raise the order to five by a suitable combination of these iterative schemes? Later, we will reply to this problem.
Theorem 1. If the conjecture of Kung and Traub is true, then the two-step optimal fourth-order iterative scheme

$$
\left\{\begin{array}{l}
y_{n}=x_{n}-\frac{f\left(x_{n}\right)}{f^{\prime}\left(x_{n}\right)}, \\
x_{n+1}=x_{n}-H\left[f\left(x_{n}\right), f^{\prime}\left(x_{n}\right), f\left(y_{n}\right)\right],
\end{array}\right.
$$

which is based on the evaluations of $\left[f\left(x_{n}\right), f^{\prime}\left(x_{n}\right), f\left(y_{n}\right)\right]$, must have the following form of error equation:

$$
e_{n+1}=\left(a_{0} c_{2}^{3}-c_{2} c_{3}\right) e_{n}^{4}+\mathcal{O}\left(e_{n}^{5}\right)
$$

where $a_{0}$ is some constant, which may be zero.

Proof. Suppose that equation (25) is not true, such that we have

$$
e_{n+1}=\left(a_{0} c_{2}^{3}-b_{0} c_{2} c_{3}\right) e_{n}^{4}+\mathcal{O}\left(e_{n}^{5}\right),
$$

where $b_{0} \neq 1$.

The weighting factors $w_{1}, w_{2}$, and $w_{3}$ are subjected to

$$
w_{1}+w_{2}+w_{3}=1
$$

Then, we consider the weighting average of the error equations in equation (23) with $i=1,2$ and equation (26) to be zero in $e_{n}^{4}$ :

$$
w_{1}\left(a_{1} c_{2}^{3}-c_{2} c_{3}\right)+w_{2}\left(a_{2} c_{2}^{3}-c_{2} c_{3}\right)+w_{3}\left(a_{0} c_{2}^{3}-b_{0} c_{2} c_{3}\right)=0
$$

which leads to

$$
\begin{array}{r}
a_{1} w_{1}+a_{2} w_{2}+a_{0} w_{3}=0 \\
w_{1}+w_{2}+b_{0} w_{3}=0
\end{array}
$$

The determinant of the coefficient matrix of the linear equations (27) and (29) is $\left(b_{0}-1\right)\left(a_{2}-a_{1}\right) \neq 0$ because $b_{0} \neq 1$ and $a_{1} \neq a_{2}$. From equations (27) and (29), we have the unique solution of $\left(w_{1}, w_{2}, w_{3}\right)$. Thus, we can derive a new iterative scheme by a weighting combination of three optimal fourth-order iterative schemes with the solved factors $\left(w_{1}, w_{2}, w_{3}\right)$ whose convergence order is raised to five. This contradicts the conjecture of Kung and Traub, who asserted that the optimal order for the iterative scheme with $m=3$ is $2^{m-1}=4$ for a multipoint iteration without memory based on $m$ evaluations of functions.

Obviously, Theorem 1 demonstrates that we cannot raise the convergence order to five by a weighting combination of any three optimal fourth-order convergence iterative schemes. 
Theorem 2. The following two-step iterative scheme:

$$
x_{n+1}=x_{n}-\frac{f\left(x_{n}\right)}{f^{\prime}\left(x_{n}\right)}-H\left(\eta_{n}\right) \frac{f\left(y_{n}\right)}{f^{\prime}\left(x_{n}\right)},
$$

for solving $f(x)=0$ has fourth-order convergence, where $y_{n}$ is computed by equation (11), and $H$ is a weight function in terms of

$$
\eta_{n}:=\frac{f\left(y_{n}\right)}{f\left(x_{n}\right)}
$$

with

$$
\begin{gathered}
H(0)=1, \\
H^{\prime}(0)=2 .
\end{gathered}
$$

The corresponding error equation is

$$
e_{n+1}=\left[\left(5-\frac{H^{\prime \prime}(0)}{2}\right) c_{2}^{3}-c_{2} c_{3}\right] e_{n}^{4}+\mathcal{O}\left(e_{n}^{5}\right)
$$

Proof. For the proof of the convergence, we let $r$ be a simple solution of $f(x)=0$, i.e., $f(r)=0$ and $f^{\prime}(r) \neq 0$. We suppose that $x_{n}$ is sufficiently close to the exact solution $r$, such that

$$
e_{n}=x_{n}-r
$$

is a small quantity, and it follows that

$$
e_{n+1}=e_{n}+x_{n+1}-x_{n}
$$

By using the Taylor series, we have

$$
\begin{gathered}
f\left(x_{n}\right)=f^{\prime}(r)\left[e_{n}+c_{2} e_{n}^{2}+c_{3} e_{n}^{3}+c_{4} e_{n}^{4}+\cdots\right], \\
f^{\prime}\left(x_{n}\right)=f^{\prime}(r)\left[1+2 c_{2} e_{n}+3 c_{3} e_{n}^{2}+4 c_{4} e_{n}^{3}+\cdots\right] .
\end{gathered}
$$

It immediately leads to

$$
\frac{f\left(x_{n}\right)}{f^{\prime}\left(x_{n}\right)}=\frac{e_{n}+c_{2} e_{n}^{2}+c_{3} e_{n}^{3}+c_{4} e_{n}^{4}+\cdots}{1+2 c_{2} e_{n}+3 c_{3} e_{n}^{2}+4 c_{4} e_{n}^{3}+\cdots+\cdots}=e_{n}-c_{2} e_{n}^{2}+A_{3} e_{n}^{3}+A_{4} e_{n}^{4}+\cdots
$$

From equations (11) and (38), we have

$$
\begin{gathered}
y_{n}=r+c_{2} e_{n}^{2}-A_{3} e_{n}^{3}-A_{4} e_{n}^{4}+\cdots, \\
f\left(y_{n}\right)=f^{\prime}(r)\left[c_{2} e_{n}^{2}-A_{3} e_{n}^{3}-\left(A_{4}-c_{2}^{3}\right) e_{n}^{4}+\cdots\right] .
\end{gathered}
$$

$$
\begin{aligned}
& \frac{f\left(y_{n}\right)}{f^{\prime}\left(x_{n}\right)}=\frac{c_{2} e_{n}^{2}-A_{3} e_{n}^{3}-\left(A_{4}-c_{2}^{3}\right) e_{n}^{4}+\cdots}{1+2 c_{2} e_{n}+3 c_{3} e_{n}^{2}+4 c_{4} e_{n}^{3}+\cdots}=c_{2} e_{n}^{2}+\left(2 c_{3}-4 c_{2}^{2}\right) e_{n}^{3}+\left(13 c_{2}^{3}-14 c_{2} c_{3}+3 c_{4}\right) e_{n}^{4}+\cdots, \\
& \frac{f\left(y_{n}\right)}{f\left(x_{n}\right)}=\frac{c_{2} e_{n}^{2}-A_{3} e_{n}^{3}-\left(A_{4}-c_{2}^{3}\right) e_{n}^{4}+\cdots}{e_{n}+c_{2} e_{n}^{2}+c_{3} e_{n}^{3}+c_{4} e_{n}^{4}+\cdots}=c_{2} e_{n}+\left(2 c_{3}-3 c_{2}^{2}\right) e_{n}^{2}+\left(3 c_{4}-10 c_{2} c_{3}+8 c_{2}^{3}\right) e_{n}^{3}+\cdots
\end{aligned}
$$

From equations (31) and (42), we have $\eta_{n}=c_{2} e_{n}+\left(2 c_{3}-3 c_{2}^{2}\right) e_{n}^{2}+\left(3 c_{4}-10 c_{2} c_{3}+8 c_{2}^{3}\right) e_{n}^{3}+\cdots$.
Because the least order of the term $\left(f\left(y_{n}\right) / f^{\prime}\left(x_{n}\right)\right)$ as shown in equation (41) is two, we only need to expand $H\left(\eta_{n}\right)$ around zero to the second-order by using equation (43) and

$$
H\left(\eta_{n}\right)=H(0)+H^{\prime}(0) \eta_{n}+\frac{H^{\prime \prime}(0)}{2} \eta_{n}^{2}+\cdots=H(0)+c_{2} H^{\prime}(0) e_{n}+\left[\frac{c_{2}^{2}}{2}\left[H^{\prime \prime}(0)-6 H^{\prime}(0)\right]+2 c_{3} H^{\prime}(0)\right] e_{n}^{2}+\cdots
$$


Inserting equations (11), (39), (44), and (41) into equation (30), we have

$$
\begin{aligned}
e_{n+1}= & c_{2} e_{n}^{2}-A_{3} e_{n}^{3}-A_{4} e_{n}^{4}-\left(H(0)+c_{2} H^{\prime}(0) e_{n}+\left[\frac{c_{2}^{2}}{2}\left[H^{\prime \prime}(0)-6 H^{\prime}(0)\right]+2 c_{3} H^{\prime}(0)\right] e_{n}^{2}\right), \\
& \times\left(c_{2} e_{n}^{2}+\left[2 c_{3}-4 c_{2}^{2}\right] e_{n}^{3}+\left[13 c_{2}^{3}-14 c_{2} c_{3}+3 c_{4}\right] e_{n}^{4}\right)+\cdots
\end{aligned}
$$

Through some manipulations, we can derive

$$
\begin{aligned}
e_{n+1}= & {\left[c_{2}-c_{2} H(0)\right] e_{n}^{2}-\left[2 c_{2}^{2}-4 c_{2}^{2} H(0)+H^{\prime}(0) c_{2}^{2}+2 H(0) c_{3}-2 c_{3}\right] e_{n}^{3}, } \\
& -\left[7 c_{2} c_{3}-4 c_{2}^{3}-3 c_{4}+H(0)\left(13 c_{2}^{3}-14 c_{2} c_{3}+3 c_{4}\right)+c_{2} H^{\prime}(0)\left(2 c_{3}-4 c_{2}^{2}\right)\right] e_{n}^{4}, \\
& -c_{2}\left[\frac{c_{2}^{2}}{2}\left[H^{\prime \prime}(0)-6 H^{\prime}(0)\right]+2 c_{3} H^{\prime}(0)\right] e_{n}^{4}+\cdots,
\end{aligned}
$$

which, due to equation (32), can be arranged to that in equation (33).

Theorem 3 (see [12]). ie following two-step iterative scheme:

$$
x_{n+1}=x_{n}-\frac{f\left(x_{n}\right)}{f^{\prime}\left(x_{n}\right)}-\frac{f^{2}\left(x_{n}\right)+(2+\alpha) f\left(x_{n}\right) f\left(x_{n}\right)+\theta f^{2}\left(x_{n}\right)}{f^{2}\left(x_{n}\right)+\alpha f\left(x_{n}\right) f\left(x_{n}\right)+\beta f^{2}\left(x_{n}\right)} \frac{f\left(y_{n}\right)}{f^{\prime}\left(x_{n}\right)},
$$

for solving $f(x)=0$ has fourth-order convergence, where $y_{n}$ is computed by equation (11). The error equation reads as

$$
e_{n+1}=\left[(5+2 \alpha-\theta+\beta) c_{2}^{3}-c_{2} c_{3}\right] e_{n}^{4}+\mathcal{O}\left(e_{n}^{5}\right),
$$

which is not supplied in [12].

Proof. It is easy to check that the weight function in iterative scheme (47):

$$
H(\eta)=\frac{1+(2+\alpha) \eta+\theta \eta^{2}}{1+\alpha \eta+\beta \eta^{2}}
$$

satisfies equation (32); hence, iterative scheme (47) is a special case of iterative scheme (30).

We can derive

$$
H^{\prime \prime}(\eta)=\frac{1}{A^{4}(\eta)}\left\{A^{2}(\eta)[A(\eta) B \prime \prime(\eta)-B(\eta) A \prime(\eta)]-2\left[A(\eta) B^{\prime}(\eta)-B(\eta) A^{\prime}(\eta)\right] A(\eta) A^{\prime}(\eta)\right\},
$$

where

$$
\begin{aligned}
& A:=1+\alpha \eta+\beta \eta^{2}, \\
& B:=1+(2+\alpha) \eta+\theta \eta^{2} .
\end{aligned}
$$

Inserting $\quad A(0)=1, A^{\prime}(0)=\alpha, A^{\prime \prime}(0)=2 \beta, B(0)=1$, $B^{\prime}(0)=2+\alpha, B^{\prime \prime}(0)=2 \theta$ into equation (50) by taking $\eta=0$, we have

$$
H^{\prime \prime}(0)=-2(2 \alpha-\theta+\beta)
$$

Inserting equation (52) into equation (33), we can derive

$$
e_{n+1}=\left[(5+2 \alpha-\theta+\beta) c_{2}^{3}-c_{2} c_{3}\right] e_{n}^{4}+\mathcal{O}\left(e_{n}^{5}\right) \text {. }
$$

This ends the proof of this theorem.

Theorem 2 includes those in $[9,17]$ as special cases. The family developed by Chicharro et al. [9]:

$$
x_{n+1}=x_{n}-G\left(\eta_{n}\right) \frac{f\left(x_{n}\right)}{f^{\prime}\left(x_{n}\right)},
$$


with $G(0)=G^{\prime}(0)=1$ and $G^{\prime \prime}(0)=4$ is a special case because we can derive

$$
H\left(\eta_{n}\right) \eta_{n}=G\left(\eta_{n}\right)-1
$$

Accordingly,

$$
\begin{aligned}
H\left(\eta_{n}\right)+\eta_{n} H^{\prime}\left(\eta_{n}\right) & =G^{\prime}\left(\eta_{n}\right), \\
2 H^{\prime}\left(\eta_{n}\right)+\eta_{n} H^{\prime \prime}\left(\eta_{n}\right) & =G^{\prime \prime}\left(\eta_{n}\right),
\end{aligned}
$$

and $H(0)=1$ and $H^{\prime}(0)=2$ imply $G(0)=G^{\prime}(0)=1$ and $G^{\prime \prime}(0)=4$. For $H$, we have only two constraints, but for $G$, there are three constraints. Hence, iterative scheme (30) is more general than the iterative scheme (54). Moreover, a further differential of the last term in equation (56),

$$
3 H^{\prime \prime}\left(\eta_{n}\right)+\eta_{n} H^{\prime \prime \prime}\left(\eta_{n}\right)=G^{\prime \prime \prime}\left(\eta_{n}\right),
$$

leads to

$$
3 H^{\prime \prime}(0)=G^{\prime \prime \prime}(0)
$$

and hence the error equation of iterative scheme (54) is

$$
e_{n+1}=\left[\left(5-\frac{G^{\prime \prime \prime}(0)}{6}\right) c_{2}^{3}-c_{2} c_{3}\right] e_{n}^{4}+\mathcal{O}\left(e_{n}^{5}\right)
$$

In [9], Chicharro et al. derived the error equation as $e_{n+1}=\left(5 c_{2}^{3}-c_{2} c_{3}\right) e_{n}^{4}+\mathcal{O}\left(e_{n}^{5}\right)$ (equation (2) in [9]), which is incorrect to miss the term $-\left(G^{\prime \prime \prime}(0) c_{2}^{3} e_{n}^{4} / 6\right)$ in the error equation.
The general function of $H(\eta)$ is given by

$$
H(\eta)=1+2 \eta+\int_{0}^{\eta} \int_{0}^{\xi} F(z) \mathrm{d} z \mathrm{~d} \xi,
$$

where $F(z)$ is any integrable function. There are two interesting iterative schemes generated from $F(z)=\cos z$ $(\mathrm{COSM})$ and $F(z)=\sin z(\mathrm{SINM})$ :

$$
\begin{aligned}
& x_{n+1}=x_{n}-\frac{f\left(x_{n}\right)}{f^{\prime}\left(x_{n}\right)}-\left(2+2 \frac{f\left(y_{n}\right)}{f\left(x_{n}\right)}-\cos \frac{f\left(y_{n}\right)}{f\left(x_{n}\right)}\right) \frac{f\left(y_{n}\right)}{f^{\prime}\left(x_{n}\right)}, \\
& x_{n+1}=x_{n}-\frac{f\left(x_{n}\right)}{f^{\prime}\left(x_{n}\right)}-\left(1+3 \frac{f\left(y_{n}\right)}{f\left(x_{n}\right)}-\sin \frac{f\left(y_{n}\right)}{f\left(x_{n}\right)}\right) \frac{f\left(y_{n}\right)}{f^{\prime}\left(x_{n}\right)} .
\end{aligned}
$$

\section{Combinations of Iterative Schemes}

In this section, we give some methods to combine the iterative schemes as listed in Table 1, which are special cases of the iterative schemes (47) and (30).

From Table 1, we can observe that there exists a cubic term $c_{2}^{3}$ in the error equation for most iterative schemes. Indeed, this term is a dominant factor to enlarge the error, and thus we can combine two iterative schemes by eliminating this term.

Theorem 4. For the following two-step iterative scheme:

$$
\begin{aligned}
x_{n+1}= & x_{n}-\frac{f\left(x_{n}\right)}{f^{\prime}\left(x_{n}\right)}-w_{1} \frac{f^{2}\left(x_{n}\right)+\left(2+\alpha_{1}\right) f\left(x_{n}\right) f\left(y_{n}\right)+\theta_{1} f^{2}\left(y_{n}\right)}{f^{2}\left(x_{n}\right)+\alpha_{1} f\left(x_{n}\right) f\left(y_{n}\right)+\beta_{1} f^{2}\left(y_{n}\right)} \frac{f\left(y_{n}\right)}{f^{\prime}\left(x_{n}\right)} \\
& -w_{2} \frac{f^{2}\left(x_{n}\right)+\left(2+\alpha_{2}\right) f\left(x_{n}\right) f\left(y_{n}\right)+\theta_{2} f^{2}\left(y_{n}\right)}{f^{2}\left(x_{n}\right)+\alpha_{2} f\left(x_{n}\right) f\left(y_{n}\right)+\beta_{2} f^{2}\left(y_{n}\right)} \frac{f\left(y_{n}\right)}{f^{\prime}\left(x_{n}\right)},
\end{aligned}
$$

if

$$
\begin{aligned}
a_{1}:=5+2 \alpha_{1}-\theta_{1}+\beta_{1} & \neq a_{2}:=5+2 \alpha_{2}-\theta_{2}+\beta_{2}, \\
w_{1} & =-\frac{a_{2}}{a_{1}-a_{2}}, \\
w_{2} & =\frac{a_{1}}{a_{1}-a_{2}},
\end{aligned}
$$

then the error equation reads as

$$
e_{n+1}=-c_{2} c_{3} e_{n}^{4}+\mathcal{O}\left(e_{n}^{5}\right)
$$

Proof. The weighting factors are subjected to

$$
w_{1}+w_{2}=1
$$

We seek the combination of iterative scheme (47) with two sets of the parameters $\left(\alpha_{1}, \beta_{1}, \theta_{1}\right)$ and $\left(\alpha_{2}, \beta_{2}, \theta_{2}\right)$ and demand the coefficient preceding $c_{2}^{3} e_{n}^{4}$ being zero,

$w_{1} a_{1}+w_{2} a_{2}=w_{1}\left(5+2 \alpha_{1}-\theta_{1}+\beta_{1}\right)+w_{2}\left(5+2 \alpha_{2}-\theta_{2}+\beta_{2}\right)=0$.

Solving equations (66) and (67), we can derive equation (64), and the error equation (48) reduces to that in equation (65).

We cannot exhaust all the combinations of the iterative schemes; however, we list the following two: one is the combination of equations (16) and (19), namely, the KOM:

$$
x_{n+1}=x_{n}+\frac{f\left(x_{n}\right)}{2 \gamma f^{\prime}\left(x_{n}\right)}+\frac{1}{2 \gamma} \frac{f\left(x_{n}\right)+\gamma f\left(y_{n}\right)}{f\left(x_{n}\right)+(\gamma-2) f\left(y_{n}\right)} \frac{f\left(y_{n}\right)}{f^{\prime}\left(x_{n}\right)}-\frac{(1+2 \gamma)\left[f\left(x_{n}\right) f\left(x_{n}\right)-f\left(y_{n}\right)\right]}{2 \gamma f^{\prime}\left(x_{n}\right)\left[f\left(x_{n}\right)-2 f\left(y_{n}\right)\right]} .
$$


TABLE 1: The comparison of different iterative schemes on the error equations.

\begin{tabular}{|c|c|c|c|c|}
\hline Algorithm & $\alpha$ & $\beta$ & $\theta$ & Error equation $\left(e_{n+1}\right)$ \\
\hline (12) & -2 & 1 & 0 & $\left(2 c_{2}^{3}-c_{2} c_{3}\right) e_{n}^{4}+\mathcal{O}\left(e_{n}^{5}\right)$ \\
\hline (13) & -2 & 2 & 0 & $\left(3 c_{2}^{3}-c_{2} c_{3}\right) e_{n}^{4}+\mathcal{O}\left(e_{n}^{5}\right)$ \\
\hline (14) & 0 & 0 & 1 & $\left(4 c_{2}^{3}-c_{2} c_{3}\right) e_{n}^{4}+\mathcal{O}\left(e_{n}^{5}\right)$ \\
\hline (15) & 0 & 0 & 0 & $\left(5 c_{2}^{3}-c_{2} c_{3}\right) e_{n}^{4}+\mathcal{O}\left(e_{n}^{5}\right)$ \\
\hline (16) & $\gamma-2$ & 0 & 0 & $\left((1+2 \gamma) c_{2}^{3}-c_{2} c_{3}\right) e_{n}^{4}+\mathscr{O}\left(e_{n}^{5}\right)$ \\
\hline (17) & $-1 / 2$ & $-1 / 4$ & $3 / 4$ & $\left(3 c_{2}^{3}-c_{2} c_{3}\right) e_{n}^{4}+\mathcal{O}\left(e_{n}^{5}\right)$ \\
\hline$(18)$ & -1 & 0 & 0 & $\left(3 c_{2}^{3}-c_{2} c_{3}\right) e_{n}^{4}+\mathcal{O}\left(e_{n}^{5}\right)$ \\
\hline (19) & -2 & 0 & 0 & $\left(c_{2}^{3}-c_{2} c_{3}\right) e_{n}^{4}+\mathcal{O}\left(e_{n}^{5}\right)$ \\
\hline$(20)$ & -1 & 0 & -1 & $\left(4 c_{2}^{3}-c_{2} c_{3}\right) e_{n}^{4}+\mathcal{O}\left(e_{n}^{5}\right)$ \\
\hline$(21)$ & 2 & 1 & 4 & $\left(6 c_{2}^{3}-c_{2} c_{3}\right) e_{n}^{4}+\mathcal{O}\left(e_{n}^{5}\right)$ \\
\hline$(22)$ & -2 & 1 & -1 & $\left(3 c_{2}^{3}-c_{2} c_{3}\right) e_{n}^{4}+\mathcal{O}\left(e_{n}^{5}\right)$ \\
\hline
\end{tabular}

The other one is the combination of equations (12) and (19), namely, the COM:

$$
x_{n+1}=x_{n}+\frac{f\left(x_{n}\right)}{f^{\prime}\left(x_{n}\right)}+\left(\frac{f\left(x_{n}\right)}{f\left(x_{n}\right)-f\left(y_{n}\right)}\right)^{2} \frac{f\left(y_{n}\right)}{f^{\prime}\left(x_{n}\right)}-\frac{2 f\left(x_{n}\right)\left[f\left(x_{n}\right)-f\left(y_{n}\right)\right]}{f^{\prime}\left(x_{n}\right)\left[f\left(x_{n}\right)-2 f\left(y_{n}\right)\right]}
$$

\section{Second Family of Optimal Fourth-Order Iterative Schemes}

In Theorem 2, we have derived a new family of optimal fourth-order iterative schemes with the assumption that the $H$-function satisfies $H(0)=1$ and $H^{\prime}(0)=2$. We can relax the conditions to $H(0)=1$ and derive the following result.

Theorem 5. Suppose that there are two different functions $H_{1}(\eta)$ and $H_{2}(\eta)$ satisfying

$$
\begin{aligned}
& H_{1}(0)=1, \\
& H_{2}(0)=1, \\
& H_{1}^{\prime}(0) \neq H_{2}^{\prime}(0) .
\end{aligned}
$$

The following two-step iterative scheme:

$$
x_{n+1}=x_{n}-\frac{f\left(x_{n}\right)}{f^{\prime}\left(x_{n}\right)}-\left[w_{1} H_{1}\left(\eta_{n}\right)+w_{2} H_{2}\left(\eta_{n}\right)\right] \frac{f\left(y_{n}\right)}{f^{\prime}\left(x_{n}\right)},
$$

for solving $f(x)=0$ has fourth-order convergence, where $y_{n}$ is computed by equation (11), and $\eta$ is defined by equation (31). The corresponding error equation is

$$
e_{n+1}=\left[\left(5-\frac{w_{1} H_{1}^{\prime \prime}(0)+w_{2} H_{2}^{\prime \prime}(0)}{2}\right) c_{2}^{3}-c_{2} c_{3}\right] e_{n}^{4}+\mathcal{O}\left(e_{n}^{5}\right)
$$

where

$$
\begin{aligned}
& w_{1}=\frac{H_{2}^{\prime}(0)-2}{H_{2}^{\prime}(0)-H_{1}^{\prime}(0)}, \\
& w_{2}=\frac{2-H_{1}^{\prime}(0)}{H_{2}^{\prime}(0)-H_{1}^{\prime}(0)} .
\end{aligned}
$$

Proof. From equations (46) and (70), it follows that the error equations corresponding to $H_{1}$ and $H_{2}$ are, respectively,

$$
\begin{aligned}
& e_{n+1}=\left[2-H_{1}^{\prime}(0)\right] c_{2}^{2} e_{n}^{3}-A_{1} e_{n}^{4}+\cdots, \\
& e_{n+1}=\left[2-H_{2}^{\prime}(0)\right] c_{2}^{2} e_{n}^{3}-A_{2} e_{n}^{4}+\cdots,
\end{aligned}
$$

where

$$
\begin{aligned}
& A_{1}:=9 c_{2}^{3}-7 c_{2} c_{3}+c_{2} H_{1}^{\prime}(0)\left(2 c_{3}-4 c_{2}^{2}\right)+c_{2}\left[\frac{c_{2}^{2}}{2}\left[H_{1}^{\prime \prime}(0)-6 H_{1}^{\prime}(0)\right]+2 c_{3} H_{1}^{\prime}(0)\right], \\
& A_{2}:=9 c_{2}^{3}-7 c_{2} c_{3}+c_{2} H_{2}^{\prime}(0)\left(2 c_{3}-4 c_{2}^{2}\right)+c_{2}\left[\frac{c_{2}^{2}}{2}\left[H_{2}^{\prime \prime}(0)-6 H_{2}^{\prime}(0)\right]+2 c_{3} H_{2}^{\prime}(0)\right] .
\end{aligned}
$$


TABLE 2: The comparison of different methods for the number of iterations.

\begin{tabular}{|c|c|c|c|c|c|}
\hline Functions & $f_{1}, x_{0}=-0.3$ & $f_{2}, x_{0}=0$ & $f_{3}, x_{0}=3$ & $f_{4}, x_{0}=3.5$ & $f_{5}, x_{0}=1$ \\
\hline NM & 55 & 5 & 7 & 11 & 7 \\
\hline KM & 49 & 3 & 4 & 7 & 8 \\
\hline GM & 38 & 3 & 6 & 7 & 11 \\
\hline CM1 & 12 & 3 & 4 & 5 & 4 \\
\hline CM2 & 24 & 3 & 4 & 6 & 5 \\
\hline $\mathrm{OM}$ & 56 & 3 & 4 & 5 & 4 \\
\hline $\mathrm{AM}$ & 24 & 3 & 4 & 7 & 5 \\
\hline COSM & 45 & 2 & 3 & 6 & 5 \\
\hline SINM & 45 & 2 & 3 & 6 & 5 \\
\hline KOM & 5 & 3 & 4 & 5 & 6 \\
\hline $\mathrm{COM}$ & 5 & 3 & 4 & 4 & 4 \\
\hline
\end{tabular}

We seek a combination of the two iterative schemes corresponding to $H_{1}$ and $H_{2}$ and ask the coefficient preceding $e_{n}^{3}$ to be zero, such that we have to solve $w_{1}$ and $w_{2}$ from

$$
\begin{aligned}
w_{1}+w_{2} & =1, \\
w_{1}\left[2-H_{1}^{\prime}(0)\right]+w_{2}\left[2-H_{2}^{\prime}(0)\right] & =0,
\end{aligned}
$$

whose solutions are given by equation (74). At the same time, the combined error equation is given by

$$
\begin{aligned}
e_{n+1} & =-w_{1} A_{1} e_{n}^{4}-w_{2} A_{2} e_{n}^{4}+\cdots \\
& =-\left[9 c_{2}^{3}-7 c_{2} c_{3}+2 c_{2}\left(2 c_{3}-4 c_{2}^{2}\right)+\frac{c_{2}^{3}}{2}\left[w_{1} H_{1}^{\prime \prime}(0)+w_{2} H_{2}^{\prime \prime}(0)\right]+4 c_{2} c_{3}-6 c_{2}^{3}\right] e_{n}^{4}+\cdots
\end{aligned}
$$

which can be arranged to that in equation (73).

The family in equation (72) includes some optimal fourth-order iterative schemes with two parameters $w_{1}$ and $w_{2}$, whose error equation again belongs to the type in equation (23). It can be seen that the functions with $H(0)=$ 1 are very general, and for this class of iterative schemes, the conjecture of Kung and Traub is also true.

\section{Numerical Experiments}

In this section, we give numerical tests of the proposed combined iterative schemes. The test examples are given by

$$
\begin{aligned}
& f_{1}(x)=x^{3}+4 x^{2}-10 \\
& f_{2}(x)=x^{2}-e^{x}-3 x+2 \\
& f_{3}(x)=(x-1)^{3}-2 \\
& f_{4}(x)=(x+2) e^{x}-1 \\
& f_{5}(x)=\sin ^{2} x-x^{2}+1
\end{aligned}
$$

The corresponding solutions are, respectively, $r_{1}=1.3652300134, r_{2}=0.2575302854, r_{3}=2.2599210499$, $r_{4}=-0.442854401002$, and $r_{5}=1.4044916482$.

In Table 2, for different functions, we list the number of iterations (NI) obtained by the presently developed algorithms, which are compared to the NM, the CM1 in equation (12), the CM2 in equation (15), the KM in equation (16) with $\gamma=3$, the $\mathrm{OM}$ in equation (19), the AM in equation (20), the
GM in equation (21), the KOM in equation (68) with $\gamma=3$, and the COM in equation (69).

\section{Conclusions}

Employing a new weight function, the nonlinear equations were solved by using a new family of the fourth-order iterative scheme, which is optimal according to the conjecture of Kung and Traub, and it was proven to be of fourth-order convergence with E.I. $=1.5874$. Theorem 1 indicated that if one can develop a fourth-order iterative scheme based on the evaluations of $\left[f\left(x_{n}\right), f^{\prime}\left(x_{n}\right), f\left(y_{n}\right)\right]$ whose coefficient preceding $c_{2} c_{3} e_{n}^{4}$ is not -1 , then the Kung-Traub conjecture would be disproved. We also proposed a combination of two fourth-order iterative schemes of which the dominant term $c_{2}^{3} e_{n}^{4}$ in the error equation is eliminated. Upon comparing some examples to other methods, we found that the combined iterative scheme converges faster. The present iterative scheme was competitive to other optimal fourth-order iterative schemes.

\section{Data Availability}

No data were used to support this study.

\section{Conflicts of Interest}

The authors declare that they have no conflicts of interest. 


\section{References}

[1] E. Halley, "A new exact and easy method for finding the roots of equations generally and without any previous reduction," Philosophical Transactions of the Royal Society, vol. 8, pp. 136-147, 1964.

[2] C. Chun and Y. Ham, "Some fourth-order modifications of Newton's method," Applied Mathematics and Computation, vol. 197, no. 2, pp. 654-658, 2008.

[3] M. A. Noor, K. I. Noor, and M. Waseem, "Fourth-order iterative methods for solving nonlinear equations," International Journal of Applied Mathematics and Engineering, vol. 4, pp. 43-52, 2010.

[4] C. Chun, "Some fourth-order iterative methods for solving nonlinear equations," Applied Mathematics and Computation, vol. 195 , no. 2 , pp. 454-459, 2008.

[5] R. F. King, "A family of fourth order methods for nonlinear equations," SIAM Journal on Numerical Analysis, vol. 10, no. 5, pp. 876-879, 1973.

[6] S. Li, "Fourth-order iterative method without calculating the higher derivatives for nonlinear equation," Journal of Algorithms \& Computational Technology, vol. 13, pp. 1-8, 2019.

[7] C. Chun, "Certain improvements of Chebyshev-Halley methods with accelerated fourth-order convergence," Applied Mathematics and Computation, vol. 189, no. 1, pp. 597-601, 2007.

[8] J. Kuo, Y. Li, and X. Wang, "Fourth-order iterative methods free from second derivative," Applied Mathematics and Computation, vol. 184, pp. 880-885, 2007.

[9] F. I. Chicharro, A. Cordero, N. Garrido, and J. R. Torregrosa, "Wide stability in a new family of optimal fourth-order iterative methods," Computational and Mathematical Methods, vol. 1, Article ID e1023, 2019.

[10] J. F. Traub, Iterative Methods for the Solution of Equations, Prentice-Hall, New York, NY, USA, 1964.

[11] H. T. Kung and J. F. Traub, "Optimal order of one-point and multipoint iteration," Journal of the ACM, vol. 21, no. 4, pp. 643-651, 1974.

[12] B. Ghanbari, "A new general fourth-order family of methods for finding simple roots of nonlinear equations," Journal of King Saud University - Science, vol. 23, no. 4, pp. 395-398, 2011.

[13] C. Chun, M. Y. Lee, B. Neta, and J. Džunić, "On optimal fourth-order iterative methods free from second derivative and their dynamics," Applied Mathematics and Computation, vol. 218, no. 11, pp. 6427-6438, 2012.

[14] C. Chun, "Some variants of King's fourth-order family of methods for nonlinear equations," Applied Mathematics and Computation, vol. 190, no. 1, pp. 57-62, 2007.

[15] A. M. Ostrowski, Solutions of Equations and System Equations, Academic Press, Cambridge, MA, USA, 1960.

[16] A. K. Maheshwari, "A fourth order iterative method for solving nonlinear equations," Applied Mathematics and Computation, vol. 211, no. 2, pp. 383-391, 2009.

[17] S. K. Khattri, M. A. Noor, and E. Al-Said, "Unifying fourthorder family of iterative methods," Applied Mathematics Letters, vol. 24, no. 8, pp. 1295-1300, 2011. 